\title{
TIPOS, SETORES, NACIONALIDADE E EXPERIÊNCIA: O QUE IMPORTA PARA O SUCESSO DAS ESTRATÉGIAS DE FUSÃO E AQUISIÇÃO?
}

\section{RESUMO}

Este estudo caracterizou os processos de Fusões e Aquisições (F\&A) que criaram maior valor interno e sinergia. O tema de F\&A não é novo na literatura de estratégia, o que não significa, que ele esteja consolidado, ao menos não do ponto de vista dos resultados que essa estratégia traz. O que se percebe é que existem momentos onde essa estratégia é mais comumente adotada, e em alguns setores onde ela é prevalente. A literatura traz a criação de sinergias como uma das principais razões para sua implementação, embora a aferição dessas sinergias não seja uma tarefa simples. Nesse sentido, o presente estudo avaliou 154 processos de F\&A, a partir de três indicadores relacionados à criação de valor de mercado e de eficiências operacionais. Os dados foram analisados com estatística descritiva, análise de variância e análise de cluster. Os resultados encontrados indicam que a maioria dos casos pesquisados apresentaram resultados positivos discretos ou negativos, não havendo diferenças significativas entre aqueles realizados em diferentes setores da economia. Os casos que apresentaram melhor desempenho foram aqueles em que as empresas já contavam com experiência prévia em F\&A e detinham conhecimento a respeito do negócio, o que reitera a necessidade de planejamento e análise a priori para a geração de sinergias e para a criação de valor, a partir dessa estratégia.

Palavras-chave: Fusões e Aquisições; Estratégia; Desempenho.

\section{SPECIFICATIONS, SECTORS, NATIONALITY AND EXPERIENCE: WHAT MATTERS FOR THE SUCCESS OF MERGERS AND ACQUISITIONS STRATEGY?}

\begin{abstract}
This study characterizes the Mergers and Acquisitions (M\&As) processes that achieved better performances in internal value and synergy generation. The M\&A theme is not particularly new in the strategy literature, which does not mean that it is consolidated, at least not from the point of view of these strategies results. Academic literature on the topic stablishes that the search for synergies is the key reason for these strategies, although the measurement of these synergies is not a simple task. This study evaluated $154 \mathrm{M} \&$ As processes using three variables related to market value creation and operational efficiencies creation. The M\&A processes were classified according to the type of agglomerative process, economic sector, nationality and positioning of companies in the production chain. Statistic data were analyzed with descriptive statistics, variance analysis and cluster analysis. The results indicate that most of the cases resulted in mild negative or positive results, with no significant differences between the results of processes carried out in different sectors of the economy. The cases that achieved better results were those in which companies already had previous experience in M\&A and held knowledge of the acquired enterprise, which reiterates the need for prior planning and analysis to the generation of the expected synergies and value creation.
\end{abstract}

Keywords: Mergers \& Acquisitions; Strategy; Performance. 
Tipos, Setores, Nacionalidade e Experiência: O Que Importa para o Sucesso das Estratégias De Fusão e Aquisição?

\section{TIPOS, SECTORES, NACIONALIDAD Y EXPERIENCIA: LO QUE IMPORTA PARA ÉXITO DE LA FUSIÓN Y ADQUISICIÓN DE ESTRATEGIAS?}

\section{RESUMEN}

Este estudio caracteriza los procesos de Fusiones y Adquisiciones (F\&A) que lograron suceso en términos de generación de valor interno y de sinergias. Las F\&As no representan una temática particularmente nueva, lo que no significa que se consolida, al menos no desde el punto de vista de sus resultados. La literatura académica establece que la búsqueda de sinergias es la razón principal de estas estrategias, aunque la medición de estas sinergias no es una tarea sencilla. Este estudio evaluó 154 procesos de F\&A utilizando tres variables relacionadas con la creación de valor de mercado y la creación de eficiencia operativa. Los procesos de F\&A se clasificaron según el tipo de proceso de aglomeración, sector económico, la nacionalidad y el posicionamiento de las empresas en la cadena productiva. Los datos fueron analizados con estadística descriptiva, análisis de varianza y de conglomerados. Los resultados indican que la mayoría de los casos resultaron negativos o positivos leves, sin diferencias significativas entre procesos de diferentes sectores económicos. Los casos que lograron mejores resultados fueron aquellos en los que las empresas ya tenían experiencia previa en $\mathrm{F} \& \mathrm{~A}$ y conocimientos sobre el negocio de la empresa adquirida. Eses resultados reiteran la necesidad de planificación y análisis previas para la generación de sinergias y creación de valor.

Palabras clave: Fusiones y Adquisiciones; Estratégia; Desempeño.

Valmir Emil Hoffmann ${ }^{1}$ Daniel Pires Vieira ${ }^{2}$ Kim La Croix Maluf de Menezes ${ }^{3}$

\footnotetext{
${ }^{1}$ Doutor em Administração de empresas pelo Universidad de Zaragoza, Espanha. Coordenação Programa de PósGraduação em Administração da Universidade de Brasília - UnB. Barsil. E-mail: ehoffmann@unb.br

${ }^{2}$ Doutor em Administração pela Universidade de Brasília - UnB. Brasil. E-mail: vieira.pires@gmail.com

${ }^{3}$ Graduado em Administração pela Universidade de Brasília - UnB. Brasil. E-mail: kcroixm@ gmail.com
} 


\section{INTRODUÇÃO}

O tema de Fusões e Aquisições - F\&A - não é particularmente novo na literatura de estratégia, havendo um aumento da quantidade de publicações nos últimos anos (Barkema, Schijven, 2008; Reis, Carvalho e Ferreira, 2015). Há 50 anos, Kitching (1967) analisava como as fusões e aquisições estavam sendo incorporadas nas estratégias das empresas. Embora a estratégia de F\&A não seja recente, sua aplicação tem se mantido significativa e numerosa no mercado (Shukla e Gekara, 2010), ao menos se tratarmos dos últimos trinta anos. Em 1986, Ravenscraft e Scherer (1986) escreveram que naquela década, os Estados Unidos estavam passando pela quarta onda de aquisições do século XX.

Especificamente no Brasil, Tanure e Cançado (2005), em pesquisa realizada em 106 das 500 maiores empresas brasileiras, encontraram que uma média de 2,72 fusões e aquisições por empresa entre 1995 e 2001. Observando o mercado nacional entre os anos de 2003 e 2013, nota-se que o CADE - Conselho Administrativo de Defesa Econômica - analisou no período mais de 7.200 atos de concentração, considerando apenas empresas com mais de $20 \%$ de participação no mercado e faturamento superior a $\mathrm{R} \$$ 400 milhões. Percebe-se que em distintos momentos, mercados e setores, as F\&As têm sido escolhidas como uma estratégia corporativa.

Ao observar tantas evidências pode-se pensar que essa estratégia é segura, em termos de geração de resultados positivos. Pesquisas empíricas, no entanto, apontam que nem sempre é vantajoso recorrer a $F \& A$, uma vez que diversas delas levam a resultados negativos (Vermeulen e Barkema, 2001; Barkema e Schijven, 2008). Em um estudo sobre megabancos nos Estados Unidos, Sharma (2010) mostrou que o efeito das F\&A na geração de valor para os acionistas foi insignificante para $40 \%$ da amostra estudada. Kitching (1967), em seu trabalho pioneiro, busca as razões pelas quais fusões tendem a fracassar e aponta que isso decorre da falta de alinhamento da política corporativa da empresa com as F\&A realizadas, ou até pela carência de um profissional responsável por acompanhar o processo. Apesar de representar um caminho rápido e atraente, muitos problemas podem ficar disfarçados nos processos de F\&A (Ravenscraft; Scherer, 1986; Dickerson; Gibson; Tsakalotos, 1997; Orsi, 2006). Entre eles estão os erros de avaliação que, conforme Berkovich e Narayanan (1993), levam à realização de aquisições ou fusões mesmo quando não há a possibilidade de criação de sinergia entre as empresas.

Até esse ponto, fica patente que a implementação de uma estratégia de $\mathrm{F} \& \mathrm{~A}$ pode ou não ter êxito. Nota-se, no entanto, que os diferentes estudos realizados não raramente focam em um conjunto restrito de empresas ou de um setor econômico específico, com diferentes métricas, variáveis de análise, tempo transcorrido e metodologias para avaliar os resultados das $\mathrm{F} \& \mathrm{~A}$, o que contribui para que o resultado dessas estratégias seja descrito como inconclusivo (King et al., 2004). Dessa forma, não fica claro quais as características dos processos que resultam em um desempenho superior. A diversidade nos resultados de pesquisas empíricas não nos permite um posicionamento a priori sobre o resultado dessas estratégias. Essa divergência motiva a realização do presente trabalho, o que leva à seguinte pergunta de pesquisa: quais características das estratégias de F\&A que criaram maior valor interno e sinergia para as empresas adquirentes? Para responde-la, o trabalho encontra-se dividido da seguinte forma: nas duas próximas seções são apresentados o referencial teórico e as hipóteses de pesquisa que orientam as análises. A quarta seção descreve os dados coletados e as análises realizadas. A quinta seção é voltada para a apresentação e discussão dos resultados. Por fim, a última seção traz as conclusões do trabalho, limitações e futuras investigações.

\section{REFERENCIAL}

A pesquisa sobre F\&A associa diversos objetivos a essas estratégias: entrada ou acesso a novos mercados, ganhos de escala, aumento da parcela de mercado, criação de um monopólio, geração de sinergias, aquisição de conhecimentos e tecnologias, benefícios fiscais e aumento da utilidade dos gestores da empresa, redução de riscos ou até de dar estabilidade ao sistema (Kloeckener, 1994; Ross, Westerfield e Jaffe 1995; Suen e Kimura, 1997; Camargos e Barbosa, 2005; Brito, Batistella e Famá, 2005; Orsi, 2006; Shukla e Gekara, 2010; Norris Jr., 2011; Reis, Carvalho e Ferreira, 2015; Du e Sim, 2016). Abordagens mais recentes ressaltam ainda a utilização das F\&A como uma forma de acessar recursos intangíveis das organizações e para a revitalização das empresas (Gupta e Roos, 2001; Vermeulen e Barkema, 2001; Patrocínio, Kayo e Kimura, 2005).

Outro aspecto que encontra diversidade nos estudos são as variáveis dependentes empregadas para aferir a geração de sinergias ou o desempenho. Pasin e Matias (2001) investigaram a geração de sinergias e o seu impacto na rentabilidade das empresas nos casos de F\&A. Os autores demonstraram a existência de sinergia nos processos de F\&A através da redução nos índices de custo dos produtos vendidos, redução das despesas administrativas e das despesas gerais, com consequente aumento da rentabilidade. Camargos e Barbosa (2005), por sua vez, empregaram as seguintes variáveis para avaliar as F\&A realizadas: perfil da dívida (prazo para pagamento e comprometimento financeiro); retorno sobre o ativo; retorno sobre o 
Tipos, Setores, Nacionalidade e Experiência: O Que Importa para o Sucesso das Estratégias De Fusão e Aquisição?

patrimônio líquido; lucro por ação; margem líquida; indicador de despesas administrativas e gerais sobre a receita líquida. Brito, Batistella e Famá (2005), em seu estudo do setor bancário brasileiro, mostraram que, apesar de as F\&A não terem sido vantajosas, não havendo aumento da riqueza dos acionistas das instituições adquirentes, não se pode negar a criação de benefícios econômicos, como o ganho de escala e o aumento do poder de mercado.

Embora as motivações e as métricas para mensuração de seu resultado possam ser diversas, o sucesso das F\&A está normalmente associado à presença de sinergia entre as empresas envolvidas (Barkema, Schijven, 2008; King et al., 2004; Pasin e Matias, 2001). Para King et al. (2004), o conceito de sinergia parte do princípio de que o resultado da soma é maior do que as partes envolvidas. Ross, Westerfield e Jaffe (1995) definem sinergia como qualquer benefício gerado pela aquisição. Já Suen e Kimura (1997) a definem como redução nos custos indiretos das empresas fusionadas, resultando em uma economia de escala. Bradley, Desai e Kim (1988) não definem diretamente sinergia em seu artigo, porém fazem uso do valor gerado para seus acionistas para determinar a sinergia criada. Como evidenciado nos trabalhos de Camargos e Barbosa (2009); e Motta et al. (2013), o termo sinergia tem duas acepções distintas: a primeira com foco na criação de valor para o mercado ou para os acionistas da empresa; a segunda com foco na geração de sinergias operacionais. Essas duas acepções, ainda que não sejam mutuamente exclusivas, ressaltam a perspectiva de que as estratégias de $\mathrm{F} \& \mathrm{~A}$ podem ter efeitos para o mercado e/ ou para a gestão da empresa.

Diferentes objetivos e métricas de desempenho são potenciais fatores explicativos para a ausência de consenso no desempenho a partir das F\&A. King et al. (2004) argumentam que os resultados de pesquisas acadêmicas internacionais sobre F\&A são inconclusivos quanto ao desempenho dessas estratégias. A exemplo do argumento apresentado, os estudos nacionais também não indicam de forma acurada se o emprego de F\&A é positivo ou não para as empresas. A Tabela 1 apresenta alguns de estudos nacionais no período 2010-2015 sobre F\&A encontrada a partir de busca no site Spell (www.spell.org.br).

Tabela 1 - Desempenho das F\&A em Estudos Nacionais

\begin{tabular}{|c|c|c|c|}
\hline Autores & Ano & Método & $\begin{array}{c}\text { Resultado da } \\
\text { F\&A }\end{array}$ \\
\hline Soares, Wegner e Dolci & 2016 & Estudo de Caso/ Caso único & Positivo \\
\hline Oliveira e Oliveira & 2015 & Análise Estocástica/ Caso único & Positivo \\
\hline Romano e Almeida & 2015 & Estudo de Eventos/ Caso único & Positivo \\
\hline Sehnem et al. & 2015 & Estudo de Eventos/ Caso único & Ambivalente \\
\hline Pessanha et al. & 2014 & Estudo de Eventos & Ambivalente \\
\hline Leitão e Gali & 2014 & Modelo GARCH & Negativo \\
\hline Sarfati e Shwartzbaum & 2013 & Estudo de Casos & Positivo \\
\hline Motta et al. & 2013 & Quantitativo/ 120 operações & Negativo \\
\hline Binder, Maccari e Nasser-Carvalho & 2010 & Estudo de Caso/ Caso único & Negativo \\
\hline Minadeo & 2010 & Estudo de Caso/ Caso único & Positivo \\
\hline
\end{tabular}

Pode-se observar, a partir da Tabela 1, que, para as pesquisas nacionais, há um predomínio da técnica estudo de caso como estratégia de pesquisa, sendo que, não raramente, apenas um único caso é o objeto do estudo. Embora o emprego do estudo de caso seja apropriado para a explicação em profundidade de um fenômeno, seus resultados usualmente são adstritos ao objeto ou, quando muito, ao setor estudado. Ressalte-se ainda que, no levantamento realizado, poucas pesquisas empregaram técnicas de análise quantitativa dos dados. Essas características das pesquisas brasileiras sobre F\&A reiteram a necessidade de uma abordagem mais ampla que possibilite identificar quais características dessas estratégias estão associadas ao bom desempenho. A partir dessas considerações, a seção seguinte apresenta hipóteses de pesquisa que orientarão as análises a serem realizadas

\section{HIPÓTESES DA PESQUISA}

Embora, não raramente, fusões e aquisições sejam tratadas de forma indistinta na literatura, os processos possuem algumas particularidades que as diferenciam. Camargos e Barbosa (2003) destacam que as aquisições são processos em que uma empresa absorve a outra, sendo que a empresa adquirente mantém seu nome e sua identidade, e adquire a totalidade do passivo e ativo da empresa adquirida. De forma distinta, a fusão seria o processo em que duas ou mais empresas se unem, criando uma empresa inteiramente nova (Camargos e Barbosa, 2003). Adicionalmente, Ross, Westerfield e Jaffe (1995) classificam as F\&A em três tipos: (i) Aquisição Horizontal - em que as empresas pertencem a um mesmo setor e, normalmente, são competidoras; (ii) 
Aquisição Vertical - em que as empresas envolvidas atuam diferentes estágios do mesmo processo produtivo; e (iii) Conglomerado - em que os processos produtivos das empresas envolvidas não guardam qualquer relação.

Pesquisas sobre a performance pós-F\&A normalmente abordam a questão sobre a proximidade das empresas da cadeia produtiva (King et al., 2004). Vermeulen e Barkema (2001) argumentam que o processo de integração a partir de uma F\&A pode ser dificultoso, devido às diferenças culturais $\mathrm{e}$ organizacionais entre empresas. Ainda que as diferenças entre as empresas criem a possibilidade de sinergias (King et al., 2004), elas não devem ser tamanhas que inibam a geração de sinergias e a criação de valor (Vermeulen e Barkema, 2001). F\&A com empresas do mesmo setor são descritas como positivas, uma vez que há uma maior facilidade de integração, pois não é necessário aprender sobre um novo negócio (King et al., 2004). Nesse sentido, entre os tipos de F\&A propostos por Ross, Westerfield e Jaffe (1995), as horizontais seriam as que trazem maior possibilidade de aportar sinergias, seguidas das verticais. Dessa maneira, hipotetizamos:

Hipótese 1 - há diferenças entre os desempenhos dos processos de F\&A de empresas em diferentes posições da cadeia produtiva.

H1.1 - F\&A Horizontais apresentam melhores desempenhos do que os demais tipos

H1.2 - F\&A Verticais apresentam melhores desempenhos do que F\&A em Conglomerado.

Considerando tratar-se de estratégias disseminadas em diversos setores econômicos e em diferentes momentos da economia, podemos associar a variação dos resultados das $\mathrm{F} \& \mathrm{~A}$ a variações no contexto (Lebedev et al., 2015; Du e Sim, 2016); ou o momento (Rao-Nicholson, Salaber e Cao, 2016) em que essas estratégias são empregadas. Asquith, Bruner e Mullins Jr. (1983) relacionaram o tamanho da empresa-alvo ao sucesso da oferta de fusão, e o período em que o processo ocorreu. Os autores concluem que o tamanho da empresa pode afetar o retorno dos acionistas, bem como o mercado de fusões altera-se com o passar do tempo, podendo impactar o desempenho da fusão. Essa literatura aponta que há aspectos contingencias, relativos à indústria ou ao setor econômico em que a F\&A foi realizada. Nesse sentido, surge a segunda hipótese de pesquisa desse trabalho:

H2 - Há diferenças entre os desempenhos das empresas a partir dos processos de F\&A de setores diferentes.

Em seu trabalho bibliométrico sobre F\&A dentro e fora de países em desenvolvimento, Lebedev et al. (2015) salientaram diferenças entre como empresas, que têm origem em países desenvolvidos e em desenvolvimento, implementam suas estratégias. Essas empresas preferem investimentos cross-border, com processos de aquisição, a fim de acessarem marca, tecnologia e outros recursos. Com isso pretedem a superar as desvantagens de executarem essa estratégia tardiamente, quando comparadas às suas concorrentes de países desenvolvidos (Lebedev et al., 2015). Na China, essa estratégia vem sendo adotada em larga escala por empresas estrangeiras desejosas de ingressar no país. O trabalho de Norris Jr. (2011) aponta que o investimento externo direto aplicado na forma de F\&A saltou de US\$ 8 milhões para mais de US\$ 8,2 bilhões, entre 1990 e 2005, naquele país.

Du e Sim (2016) pesquisarem 960 processos de F\&A que ocorreram no setor bancário, na China, Índia, Indonésia, Malásia, Rússia e Tailândia. Seu objetivo era verificar se a estratégia de F\&A poderia afetar os bancos adquiridos e adquirentes de maneira diferente. Os autores concluíram que essa estratégia, em países emergentes, incrementa a eficiência de forma combinada para o banco adquirido e para o adquirente, mas que essa eficiência origina-se do banco adquirido (Du e Sim, 2016). Isso significa que, de maneira conjunta, ambos bancos foram favorecidos, mas que os resultados positivos vieram dos adquiridos. Isso parece um tanto paradoxal, mas do ponto de vista da estratégia é possível que o banco adquirente tenha atingido seu objetivo de ampliar mercado, ou ingressar em um novo mercado, o que se configura como um objetivo estratégico de longo prazo, mas que no curto prazo, não determina resultados melhores em seu balanço.

Vermeulen e Barkema (2001) indicam que as F\&A entre empresas de países diferentes tendem a ser particularmente difíceis, uma vez que envolvem ajustes às características locais do país quanto à cultura organizacional. Em que pese essas dificuldades, Milhomem e Hoffmann (2011) associaram melhores resultados em F\&A para empresas estrangeiras com experiência prévia em processos similares, quando comparadas às empresas brasileiras que adotaram essa estratégia. Considerando os resultados descritos propomos:

H3 - Há diferenças entre os desempenhos das empresas a partir dos processos de F\&As de nacionalidades diferentes.

Kitching (1967) escreveu que empresas que utilizam de F\&A de forma planejada apresentam maiores chances de obter sucesso. Pardini et al. (2014) sinalizaram a importância do aprendizado conjunto das envolvidas para o sucesso das F\&A. Barkema e Schijven (2008) argumentam que o processo de aprendizagem em F\&A é presumido como sendo sempre positivo. Os autores, no entanto, destacam que experiência não necessariamente leva ao aprendizado, ou seja, que não necessariamente a experiência 
adquirida em um processo anterior é aplicável aos demais processos de $\mathrm{F} \& \mathrm{~A}$.

Tanure e Cançado (2005) argumentam pela necessidade de experiência e de equipes especializadas para o sucesso dos processos de F\&A. A experiência prévia, tanto organizacional quanto individual, facilitam o processo de identificação e integração dos recursos entre as firmas, o que pode ocasionar melhores desempenhos pós-F\&A (King et al., 2004). Em suas recomendações gerenciais, Lebedev et al. (2015) ressaltam que os gestores sem experiência em F\&A devem iniciá-la com processos de pequena escala, uma vez que boa parte dos estudos anteriores pesquisados pelos autores ressaltam a experiência prévia como importante para os processos de F\&A. Entendemos, assim, que a experiência prévia e o planejamento são fatores determinantes para a obtenção de resultados positivos a partir da estratégia de F\&A, de forma que haveria uma curva de aprendizagem na preparação e operacionalização dos processos. Empresas com experiências prévias possuiriam maior possibilidade de êxito em suas F\&A, por isso, nossa quarta hipótese ressalta que:

H4 - A existência de experiência prévia impacta positivamente o desempenho das F\&A.

\section{MÉTODO}

A presente pesquisa caracteriza-se como descritiva com a aplicação de técnicas quantitativas. O objeto de análise são as empresas que realizaram fusões e aquisições, sendo que os dados utilizados são de fonte secundária. A amostra selecionada para o presente estudo foi definida a partir da listagem de processos de F\&A, disponível no sítio eletrônico do CADE. Foram analisados todos os atos de concentração notificados ao CADE entre os anos de 2000 e 2011. A escolha do referido período deve-se à disponibilidade de informações e à necessidade de prazo para que os processos analisados viessem a surtir efeito sobre o desempenho das empresas. Atos de concentração envolvem obrigatoriamente a participação de ao menos duas empresas. Cabe ressaltar que alguns processos apresentam mais de duas empresas envolvidas, porém para o presente estudo, foram utilizados apenas processos em que apenas uma empresa adquirente estivesse envolvida. Quando da análise dos processos de aquisições, utilizamos as informações das empresas adquirentes. Outro critério estabelecido para seleção dos casos a serem analisados foi a participação das empresas na bolsa de valores. Essas empresas são obrigadas a divulgarem informações sobre o seu desempenho financeiro, o que possibilita o acesso a informações sobre seu desempenho anterior e posterior aos processos de F\&A com as informações extraídas do sítio do Economática. Foram eliminados da amostra os processos em que as empresas não dispunham de informações disponíveis para o ano em que ocorreu o processo ou para dois anos após a realização. A amostra inicial resultou em 180 processos. Os dados do sítio Economática foram coletados em abril de 2014. Os dados referentes aos atos de concentração foram coletados em março de 2014.

O CADE classifica os atos de concentração em 5 categorias: (i) fusão; (ii) aquisição; (iii) aquisição de negócio; (iv) associação; e (v) joint-venture. Observase nos dados coletados que as aquisições são por muitas vezes classificadas em subcategorias de acordo com o método de pagamento utilizado (compra de ações, aquisição por compra de quotas, aquisição por permutas de ações e aquisição de ativos), no entanto, para fins das análises a serem realizadas, foram agrupadas dentro da categoria Aquisição. As fusões ocorreram em menor quantidade e foram todas classificadas na categoria Fusões. Os processos com Aquisição de Negócios representavam a compra de uma marca, um produto ou mesmo uma fórmula. Destaca-se que a literatura revisada não faz referência a esse tipo específico de aquisição, no entanto nota-se que, por se tratar de um processo menos agressivo do que uma aquisição ou uma fusão, diversos problemas associados a essas estratégias corporativas poderiam ser evitados. Considerando a pequena quantidade desses casos, decidiu-se agrupá-lo na categoria Aquisição. As classificações Associações e Jointventures, são bem semelhantes, ambos podem ser considerados parcerias entre empresas, podendo envolver a gestão da empresa, a partilha de lucros, riscos ou projetos, ou mesmo a criação de uma nova empresa. Como não há na literatura referências sobre essas categorias e poucos processos foram classificados nelas, optou-se pela sua exclusão da base de dados.

Os processos de concentração foram também classificados considerando o setor produtivo das empresas envolvidas. A partir das informações do CADE, foram criadas 4 categorias: (i) Agricultura, Pecuária e Extração Mineral; (ii) Comércio; (iii) Indústria; (iv) Serviços e Tecnologia. A partir dessas categorias, foi possível classificar os processos de acordo com o posicionamento das empresas envolvidas na cadeia produtiva, identificado a partir das informações disponíveis no sítio do CADE: Vertical quando as empresas envolvidas se encontram em estágios distintos da cadeia produtiva; horizontal quando as empresas estão no mesmo estágio da cadeia produtiva; e em conglomerado - quando as empresas são de cadeias produtivas não relacionadas. Tendo em conta a nacionalidade das empresas envolvidas os processos foram classificados em nacionais - quando todas as empresas envolvidas eram brasileiras; e internacionais - quando ao menos uma das empresas envolvidas era estrangeira.

Como muitas empresas possuíam vários processos em determinados anos, duas variáveis foram criadas. A primeira variável - "Quantidade de 
Processos Anteriores" - agrupa as empresas em três categorias: (i) empresas com nenhum processo de F\&A Anterior; (ii) empresas com um processo de F\&A anterior; e (iii) empresas com mais um processo de F\&A anterior. Essa variável permite analisar se há um processo de aprendizagem nas F\&A que permita aferir melhores resultados com a experiência adquirida.

O uso de múltiplas medidas para avaliação do desempenho das estratégias de F\&A vem sendo encorajada pela literatura (King et al., 2004). Nesse sentido, para avaliar o desempenho final da F\&A foram utilizados três indicadores. Dois associados à criação de valor dentro das empresas - Q de Tobin e Valor de Mercado/ Valor Patrimonial. O terceiro indicador empregado - Margem Líquida - associa-se à criação de sinergias operacionais. O Q de Tobin (QT), utilizado no estudo de Camargos e Barbosa (2009), é apontado por Famá e Barros (2000) como um indicador que avalia a oportunidade de crescimento para a firma. Dessa forma, quanto maior o QT, maior a oportunidade de investimento. Por outro lado, um QT abaixo de 1 demonstra que a empresa não possui grandes oportunidades de investimento. Adicionalmente, o QT também avalia a qualidade da administração da empresa, sendo que empresas com um QT alto possuem boa administração, enquanto empresas com um baixo estão sendo mal administradas.

$\mathrm{O}$ indicador Valor de Mercado, dividido pelo Valor Patrimonial (VM/VP) das empresas, procura determinar a razão entre o valor de mercado da empresa, levantado pelo preço de suas ações e o seu valor patrimonial. Um valor menor que 1 demonstra que o mercado está pagando pela empresa menos do que ela possui em termos de patrimônio, o que indica um desempenho ruim. Valores maiores do que 1 demonstram que a empresa está tendo um bom desempenho e é valorizada pelo mercado.

Por fim, o indicador Margem Líquida (ML) busca medir se as empresas conseguiram converter uma proporção maior de suas receitas em lucro, devido a uma melhora em sua eficiência operacional, administrativa e financeira. Camargos e Barbosa (2005, 2009) argumentam que a ML identifica a eficiência operacional, administrativa e financeira das empresas, ao avaliar se houve a conversão de uma proporção maior de sua receita em lucro. Motta et al. (2013) argumentam que o Q de Tobin e VM/VP são indicadores altamente correlacionados e que dizem respeito à criação de valor para o mercado, a partir das F\&A, enquanto que a Margem Líquida estaria associada à presença de sinergias operacionais. Levando em consideração que as estratégias de F\&A demandam tempo para a maturação de seus resultados, para a realização das análises foi utilizada a variação percentual dos indicadores propostos, tomando por base o ano de realização do processo de concentração em relação ao resultado aferido no mesmo indicador após dois anos. Observamos que a análise do desempenho a partir da variação percentual dos indicadores já havia sido empregada em outros estudos, tais como Matias e Pasin (2001); Camargos e Barbosa (2005b, 2009); e Milhomem e Hoffmann (2011). A Tabela 2 resume os indicadores ora apresentados.

Tabela 2 - Variáveis de Desempenho

\begin{tabular}{|c|l|c|l|}
\hline Indicador - Sigla & \multicolumn{1}{|c|}{ Eficiência Econômica Mensurada } & Interpretação & \multicolumn{1}{|c|}{ Referencial } \\
\hline Q de Tobin - QT & $\begin{array}{l}\text { Estimativa dos ativos intangíveis das } \\
\text { empresas (mercado, qualidade da } \\
\text { administração e oportunidades de } \\
\text { investimento). }\end{array}$ & $\begin{array}{l}\text { Diretamente } \\
\text { proporcional. }\end{array}$ & $\begin{array}{l}\text { Camargos e Barbosa } \\
(2009) ; \\
\text { Famá e Barros (2000) }\end{array}$ \\
\hline $\begin{array}{c}\text { Valor de Mercado/ } \\
\text { Valor Patrimonial - } \\
\text { VM/VP }\end{array}$ & $\begin{array}{l}\text { Medida de avaliação da perspectiva e do } \\
\text { desempenho de longo prazo da empresa. }\end{array}$ & $\begin{array}{c}\text { Diretamente } \\
\text { proporcional. }\end{array}$ & $\begin{array}{l}\text { Camargos e Barbosa } \\
(2009) ; \\
\text { Motta } \text { et al. } \text { (2013) }\end{array}$ \\
\hline $\begin{array}{c}\text { Margem Líquida - ML } \\
\text { Ganho de economia de escala e de } \\
\text { escopo. }\end{array}$ & $\begin{array}{l}\text { Diretamente } \\
\text { proporcional. }\end{array}$ & $\begin{array}{l}\text { Camargos e Barbosa } \\
(2005) ; \\
\text { Motta } \text { et al. } \text { (2013) }\end{array}$ \\
\hline
\end{tabular}

Os dados foram analisados a partir de estatística descritiva, Análise de Variância - ANOVA - e Análise de Cluster. A estatística descritiva teve por objetivo a identificação da quantidade de casos em cada uma das categorias criadas, bem como de casos faltantes e de casos extremos. Casos extremos e com informações faltantes para as variáveis de desempenho foram eliminados das análises, resultando em 154 casos efetivamente analisados. Para a realização das análises, as variáveis de desempenho foram padronizadas em escores-Z.
A ANOVA foi empregada, seguindo as recomendações de Field (2005); e Malhotra (2012), para testar a diferença dos indicadores de desempenho para as diferentes categorias nas quais os processos de F\&A foram classificados: Setor Econômico; Tipo de F\&A; Quantidade de Processos Realizados; Posicionamento da F\&A quanto a Cadeia Produtiva; e Nacionalidade das Empresas. De forma a sanar problemas com as diferenças de variância e de tamanho das amostras, optamos pelo emprego dos testes de Games-Howell e de GT2 Hochberg. Ambos são testes 
Tipos, Setores, Nacionalidade e Experiência: O Que Importa para o Sucesso das Estratégias De Fusão e Aquisição?

post hoc utilizados para contrastar as diferenças entre os grupos, sendo que o primeiro é empregado para comparações entre grupos com variâncias nãohomogêneas, e o segundo para comparações entre grupos com tamanhos muito diferentes.

Por fim, a Análise de Cluster foi empregada, seguindo as orientações de Hair Jr. et al. (2009); e Mingoti (2005), com o objetivo de agrupar os casos analisados a partir das variáveis de desempenho descritas. Dessa forma os processos de Fusão e Aquisição analisados foram agrupados a partir das variáveis QT, VM/VP e ML. Para a realização das análises utilizou-se o software Statistical Package for Social Sciences - SPSS. A seção seguinte traz os resultados alcançados e as análises dos dados.

\section{RESULTADOS}

As primeiras hipóteses de pesquisa levaram em consideração o posicionamento das empresas adquirente e adquirida na cadeia produtiva. A Figura 1 permite a comparação entre as médias de desempenho dos processos por categoria. Os resultados encontrados indicam que as F\&A Horizontais apresentam um desempenho positivo para as três variáveis analisadas, o que, a priori, corrobora os argumentos de Vermeulen e Barkema (2001) e King et al. (2004).

Figura 1 - Desempenho Médio (\%) por Tipo de Processo

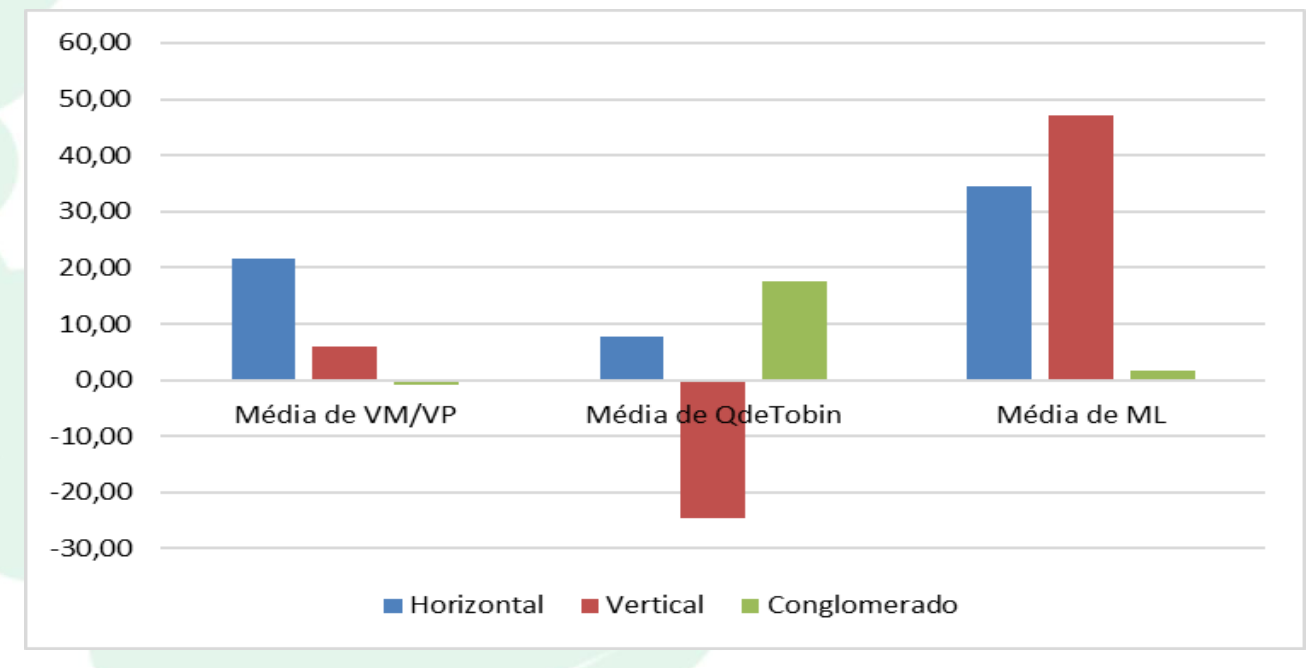

As F\&A Verticais apresentam o maior incremento médio em termos de desempenho operacional (indicado pela variáveis ML). Como sugerido por King et al. (2004), as diferenças entre as empresas criam a possibilidade de geração de sinergias. As F\&A Verticais, no entanto, mostram um desempenho contraditório, quando analisadas sob a perspectiva das variáveis de mercado. Observamos que a variável VM/VP apresenta um discreto desempenho positivo, enquanto que a variável $Q$ de Tobin indica um desempenho negativo das F\&A Verticais.

A exemplo das F\&A Verticais, as F\&A em conglomerado apresentam um resultado controverso quanto a perspectiva de mercado, sendo que a variável VM/VP apresenta um desempenho negativo e a variável Q de Tobin apresenta o melhor desempenho entre os tipos de F\&A considerados. Sob uma perspectiva de eficiência produtiva, as F\&A em Conglomerado não parecem gerar sinergias operacionais para as empresas. Ainda que que a F\&A do tipo conglomerado representa uma diversificação no risco da empresa (Kitching, 1967) e que uma das vantagens em uma F\&A, é a diversificação da linha de negócios (Orsi, 2005), podemos argumentar que o choque cultural, a falta de comunicação (Norris Jr., 2011), e os problemas envolvidos são potencializados pelas compras de empresas de cadeias produtivas diferentes, o que explicaria o baixo desempenho comparativo dessas F\&A, em termos de sinergia operacional.

Ainda que os indicadores Q de Tobin e VM/VP sejam descritos como altamente correlacionados (Motta et al., 2013), os resultados sugerem que um dissenso entre esses indicadores quanto ao tipo de F\&A avaliada. Ainda que correlacionados, o Q de Tobin é uma estimativa dos ativos intangíveis das empresas (Camargos \& Barbosa, 2009; Famá e Barros, 2000), enquanto que a, o proporção entre valor de mercado e valor patrimonial (VM/VP) é uma medida de avaliação da perspectiva do desempenho de longo prazo da empresa (Camargos \& Barbosa, 2009; Motta et al., 2013). Nesse sentido, a diversificação de atividades e de ativos de uma empresa, a partir da estratégia de F\&A em conglomerado gera resultados positivos quando avaliada a partir do $\mathrm{Q}$ de Tobin, sendo, contudo, vista com desconfiança quanto ao 
desempenho futuro da empresa. Diferentemente, a F\&A Vertical cria possibilidades de combinação de ativos complementares, o que reflete em sinergias operacionais (como verificado no indicador ML) perceptíveis pelo mercado, como indicado pela variável VM/VP.

Em que pesem os argumentos apresentados, os resultados da ANOVA indicam que, para as três variáveis de desempenho analisadas, não há diferenças significativas entre os tipos de F\&A, entretanto, quando da aplicação dos testes post hoc, observou-se que as diferenças significativas entre as F\&A Horizontal e em Conglomerado tanto para a variável VM/VP quanto para a variável ML. Nesse sentido, embora haja diferenças significativas entre os desempenhos dos processos de F\&A de empresas em posições diferentes na cadeia produtiva (corroborando a primeira Hipótese de pesquisa), as F\&A Horizontais não se diferenciaram significativa mente as F\&A em Conglomerado, o que permite corroborar apenas parcialmente a Hipótese 1.2. F\&A Verticais, por fim, apresentaram não apresentaram diferenças significativas entre suas variáveis de desempenho, o que leva à rejeição da Hipótese 1.2.

A segunda hipótese de pesquisa tratava da diferença de desempenho das F\&A de setores distintos. A Figura 2 apresenta a comparação entre as médias das três variáveis de desempenho selecionadas para os setores analisados. Embora a ANOVA tenha apresentado resultados não significativos para a comparação entre as médias dos setores, o teste post hoc de Games-Howell revelou diferenças significativas entre os setores Comércio e Indústria e Comércio e Serviços e Tecnologia, especificamente para a variável ML. Destacamos que, para o setor Comércio, apenas uma empresa representa mais de $70 \%$ dos processos de F\&A realizados. Para as demais variáveis de desempenho não foram encontradas diferenças significativas. Nesse sentido, os resultados encontrados não permitem corroborar a Hipótese 2.

Figura 2 - Desempenho Médio (\%) por setor Econômico

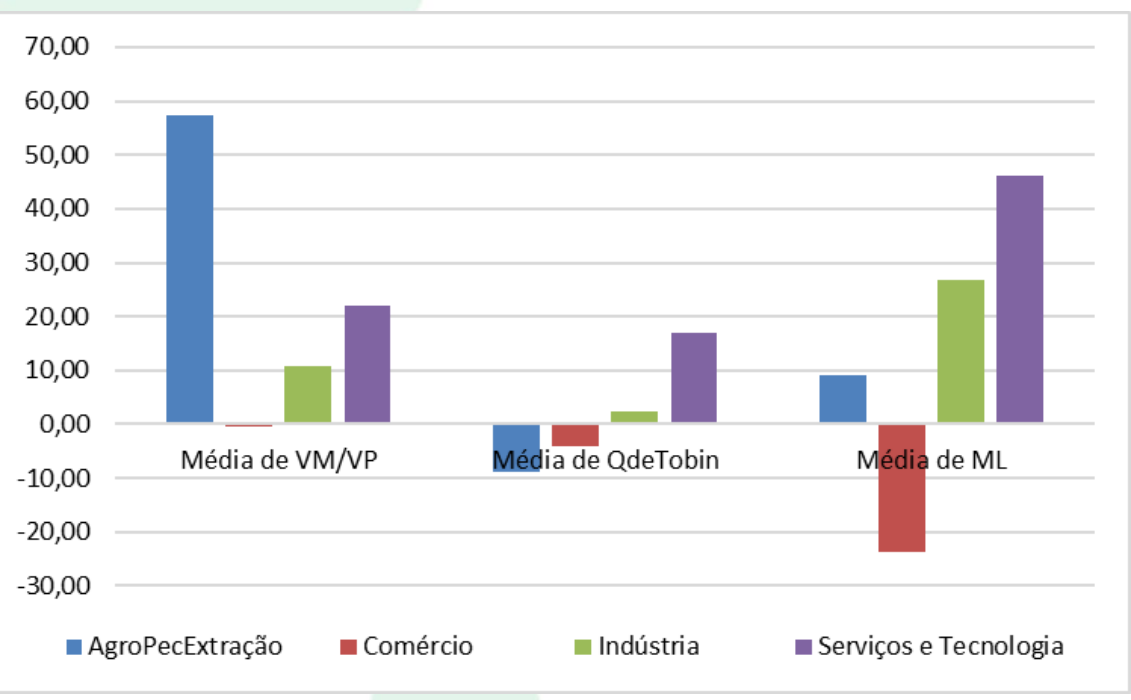

Para Kitching (1967), é mais fácil atingir sinergia quando recursos financeiros são agrupados, e mais difícil quando instalações são agrupadas. De forma similar, Patrocínio, Kayo e Kimura (2009) demonstram em seu trabalho que F\&As que envolvem empresas intangível-intensivas apresentam maior potencial de retorno, quando comparadas com empresas tangível-intensivas. Muito embora a literatura sobre F\&A indique que o contexto em que as estratégias de F\&A são realizadas importa para o seu desempenho (Lebedev et al., 2015; Du e Sim, 2016), o resultado encontrado sugere que, seja para fins de avaliação, a partir de medidas de criação de valor para o mercado ( $Q$ de Tobin e VM/VP) seja sob uma perspectiva de sinergia operacional (ML), não há diferença significativa entre as estratégias de F\&A setores econômicos distintos.

Além de comparar o resultado das F\&A entre setores, analisamos também o desempenho da estratégia de F\&A, de acordo com a nacionalidade da empresa adquirente. A Figura 3 permite a comparação entre o desempenho das F\&A de empresas nacionais e internacionais. 
Figura 3 - Desempenho Médio (\%) por Nacionalidade Adquirente

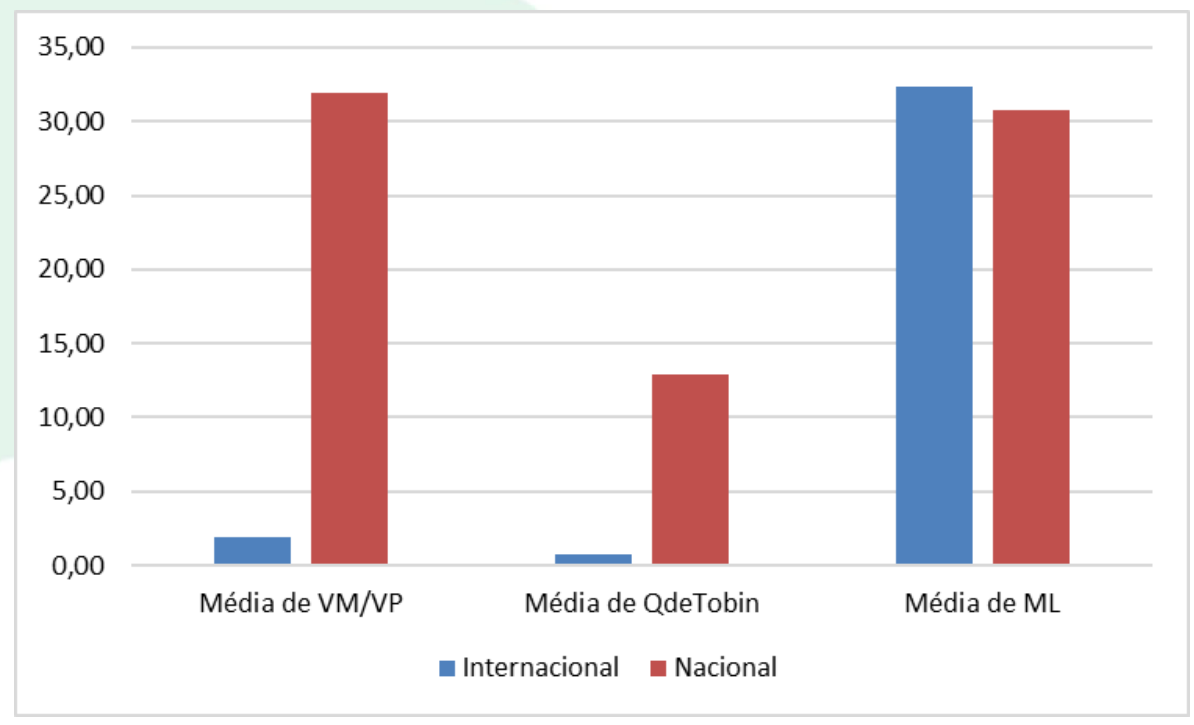

Podemos observar a partir da Figura 3 que as F\&A entre empresas nacionais apresentam melhor desempenho nas métricas de mercado, sendo que o desempenho em termos de sinergia operacional é similar para os dois grupos. Os resultados da comparação de médias, no entanto, indicam que a diferença entre os grupos é significativamente estatística somente para a variável VM/VP. Nesse sentido, a Hipótese 3 é corroborada parcialmente.

De acordo com Kitching (1967), um erro comum das empresas é subestimar as demandas que uma F\&A trará para a empresa, ou mesmo o risco de choque cultural entre elas (Suen e Kimura, 1997; Norris Jr., 2011). Essas dificuldades associadas às F\&A são potencializadas devido às diferenças culturais entre os países (Vermeulen e Barkema, 2001). Os resultados encontrados propõem uma lógica distinta. Sob uma perspectiva de mercado, as aquisições nacionais apresentaram melhores indicadores, uma vez que o processo de integração de ativos entre empresas nacionais é menos incerto e de mais fácil percepção para o mercado doméstico. Por outro lado, sob uma perspectiva de sinergia operacional, os resultados indicam não haver diferença entre as F\&A nacionais e internacionais.

Ressaltamos que a estratégia de F\&A não raramente é empregada de forma associada à estratégia de internacionalização para entrada em um novo mercado (Lebedev et al., 2015; Norris Jr., 2011). Nesses casos, o objetivo das F\&A não é o aumento de sua produtividade ou a integração de ativos, mas o acesso a um novo mercado (Lebedev et al., 2015). Esse parece ser o caso para a amostra pesquisada. Mais de $50 \%$ das adquirentes internacionais fizeram mais de uma aquisição no período analisado. As empresas internacionais fizeram em média 2,5 processos de aquisição, enquanto que as empresas nacionais fizeram em média de 1,74 processos aglomerativos, entre 2000 e 2011.

A Figura 4 apresenta a comparação entre os desempenhos médios para a quantidade de processos anteriores realizados pelas empresas. Notamos que para os indicadores associados ao desempenho de mercado ( $\mathrm{Q}$ de Tobin e VM/VP), o desempenho da estratégia de F\&A apresenta um comportamento em forma de "U" invertido. Nesse sentido, o desempenho do segundo processo de F\&A apresenta um melhor desempenho do que o primeiro. Essa melhora de desempenho, no entanto, não se mantém para os demais processos aglomerativos. A variável associada ao desempenho produtivo, por sua vez, apresenta uma trajetória de decrescimento em termos de desempenho quanto ao desempenho da estratégia. 
Tipos, Setores, Nacionalidade e Experiência: O Que Importa para o Sucesso das Estratégias De Fusão e Aquisição?

Figura 4 - Desempenho Médio (\%) a partir da Quantidade de Processos Anteriores Realizados

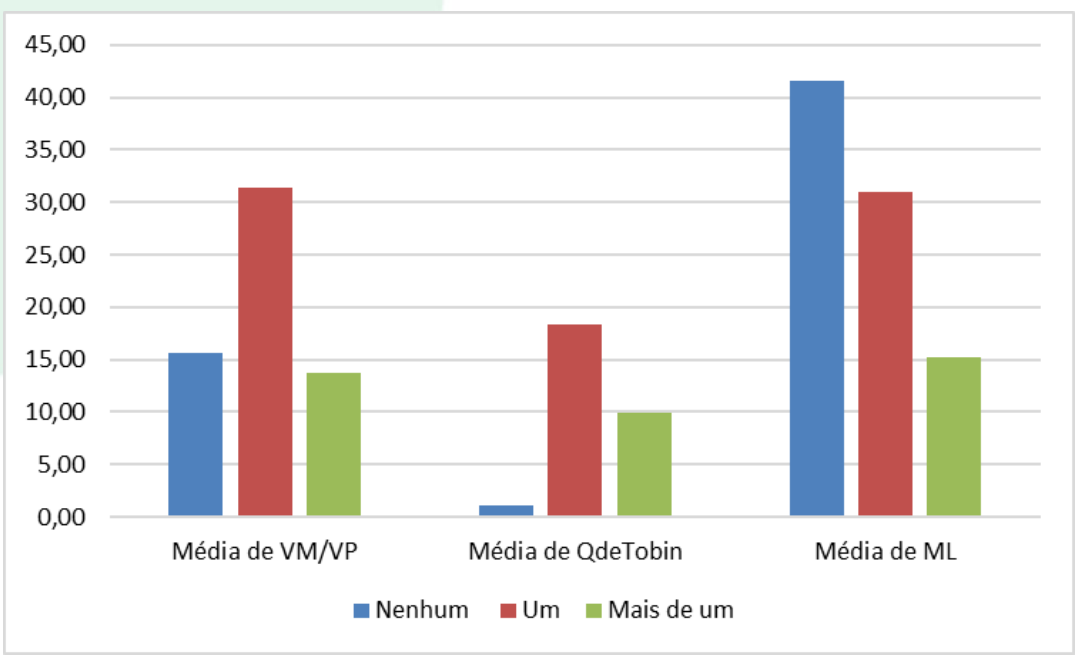

Os resultados da ANOVA comparando as médias para os três subgrupos não apresentou significância para as três variáveis estudadas. Nesse sentido, rejeitamos a Hipótese 5. Esse resultado contraria as evidências apresentadas por estudos anteriores (King et al., 2004; Tanure e Cançado, 2005; Milhomem e Hoffmann, 2011; Pardini et al., 2014; Lebedev et al., 2015), e indica que a realização de processos anteriores não garante o resultado em novos processos de F\&A. Como argumentado por Barkema e Schijven (2008), a experiência anterior não necessariamente leva ao aprendizado, além do que as características aprendidas em um processo de F\&A não necessariamente serão aplicáveis a novos processos. Não se trata de refutar a importância da execução de processos anteriores, mas de reconhecer que o aprendizado não é um resultado garantido, a partir da simples reiteração da aplicação da estratégia e que, como ressaltado por Kitching (1967), F\&A demandam estudo e planejamento.

Considerando que as características dos processos de F\&A não se diferenciaram de forma significativa a partir das Análises de Variância, optamos pelo agrupamento dos processos pela aplicação da Análise de Cluster nas variáveis de desempenho. Inicialmente, a análise de cluster foi empregada sob uma perspectiva exploratória, com o intuito de se identificar a quantidade de agrupamentos a serem criados. Nesse sentido, foi utilizada a análise de cluster hierárquica aglomerativa, pela aplicação do Método da Média das Distâncias (Between-groups linkage), com o emprego da Distância Euclidiana. A partir da inspeção visual do dendograma foram criados 5 agrupamentos.

Uma vez identificada a quantidade de agrupamentos, foi realizada nova análise de cluster a partir de uma técnica não-hierárquica. Mingoti (2005) destaca que os métodos não-hierárquicos têm por objetivo dividir os elementos analisados em uma quantidade já determinada de agrupamentos, de forma que haja semelhança entre os elementos de um mesmo grupo, e isolamento entre os grupos. Foi empregado o Método das k-Médias, mantendo a Distância Euclidiana como medida de distância entre os elementos. A ANOVA entre os clusters apresentou resultados significativos para as três variáveis. A Tabela 3 apresenta informações sobre os valores assumidos pelas variáveis utilizadas para cada um dos agrupamentos.

Tabela 3 - Valores Centrais Assumidos pelos Agrupamentos Criados

\begin{tabular}{|l|c|c|c|c|c|c|}
\hline \multicolumn{1}{|c|}{ Indicadores } & Cluster 1 & Cluster 2 & Cluster 3 & Cluster 4 & Cluster 5 & Média \\
\hline $\mathrm{Q}$ de Tobin & 8,63 & 260,79 & 100,59 & $-37,23$ & 26,60 & 7,44 \\
\hline $\mathrm{VM} / \mathrm{VP}$ & 11,16 & 195,93 & 168,62 & $-25,28$ & 32,69 & 18,45 \\
\hline $\mathrm{ML}$ & 282,03 & 380,64 & 38,29 & $-11,61$ & 19,42 & 31,43 \\
\hline $\mathrm{N}^{\circ}$ de Casos & 10 & 3 & 10 & 66 & 65 & - \\
\hline
\end{tabular}

Percebemos a partir da Tabela 3 , que $85 \%$ dos casos estão nos agrupamentos mais numerosos (Clusters 4 e 5). No caso do Cluster 4, todos os indicadores de desempenho apresentaram variação negativa dois anos após a realização da F\&A. Já o Cluster 5 apresenta variações positivas nos indicadores 
avaliados, sendo que no caso dos indicadores $\mathrm{Q}$ de Tobin e VM/VP, essa variação encontra-se acima da média da totalidade dos casos estudados $(7,44 \%$ e $18,45 \%$ respectivamente), enquanto que a variável ML, embora apresente uma variação positiva, encontra-se abaixo da média da totalidade dos casos $(31,43 \%)$. Os resultados corroboram a perspectiva de que há uma grande incerteza quanto à implementação da estratégia de F\&A, ao menos do ponto de vista dos resultados, como mostram distintos trabalhos (Oliveira e Oliveira,
2015; Romano e Almeida, 2015; Sarfati e Shwartzbaum, 2013; Leitao e Gali, 2014; Motta et al., 2013; Binder, Maccari e Nasser-Carvalho, 2010).

Conforme argumentamos, os resultados das F\&A podem variar de acordo com o momento da economia (Asquith, Bruner e Mullins Jr., 1983; RaoNicholson, Salaber e Cao, 2016). A Figura 5 apresenta um diagrama de extremos e quartis com a quantidade de casos por cluster em relação ao ano de realização do processo de F\&A.

Figura 5 - Diagrama de Extremos e Quartis - casos por cluster por ano de realização da F\&A

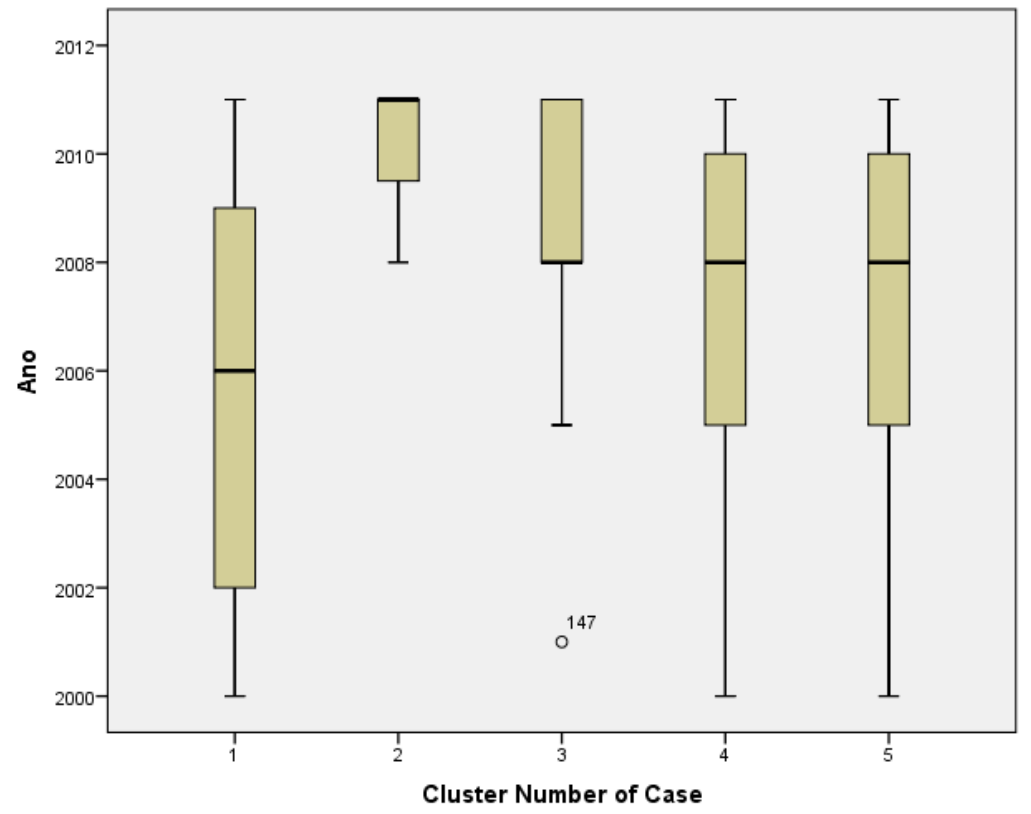

A Figura 5 evidencia que há uma maior concentração de casos a partir de 2008. Podemos observar que os dois Clusters mais numerosos (4 e 5) apresentam uma distribuição similar de casos ao longo do período analisado. Embora o grupo de melhor desempenho (Cluster 2) tenha todos os seus casos concentrados no referido período, o Cluster 3 apresenta uma distribuição igualitária de casos antes e depois do referido ano, enquanto que os Casos do Cluster 1, a exemplo dos Clusters mais numerosos, estão distribuídos ao longo de todo o período analisado. Nesse sentido, não se verifica influência do período sobre o desempenho dos processos de F\&A analisados, como ressaltado nos trabalhos de Asquith, Bruner e Mullins Jr. (1983), Lebedev et al. (2015), RaoNicholson, Salaber e Cao (2016) e Du e Sim (2016).

Não obstante aos argumentos apresentados, notamos que os resultados dos Clusters 1, 2 e 3 foram expressivos para os três indicadores analisados. O Cluster 1 é composto por empresas do setor de Serviços e Tecnologia e da Indústria, sendo que a grande maioria dos processos era o primeiro realizado no período analisado. Os resultados aferidos mostram- se efetivamente positivos no indicador ML, o que permite inferir que essas empresas obtiveram uma melhora em sua eficiência operacional, com um melhor retorno de seu lucro líquido sobre a receita líquida. Por outro lado, os indicadores $Q$ de Tobin e VM/VP obtiveram somente uma ligeira melhora com valores próximos à média da totalidade das empresas. Nesse sentido, argumentamos que as operações de F\&A do Cluster 1 alcançaram uma sinergia operacional, no entanto, sem gerar criação de valor igualmente positiva para o mercado, o que é semelhante ao que Du e Sim (2016) encontraram, ao pesquisarem F\&A em bancos.

As operações do Cluster 3 apresentaram resultados mais altos que a média para os indicadores $\mathrm{Q}$ de Tobin e VM/VP e um resultado mais discreto para o indicador ML. A maioria dos casos constantes nesse Cluster foram a primeira operação de concentração da empresa no período analisado, sendo que todas as F\&A foram entre empresas que atuam no mesmo estágio da cadeia produtiva, ou seja, uma F\&A horizontal. Ao contrário dos casos do Cluster 1, nesses há uma percepção positiva pelo mercado que, todavia, não é acompanhada por uma efetiva melhoria 
operacional das empresas. Dessa forma, a sinergia criada pelas operações do Cluster 3 indicam uma melhora em indicadores de criação de valor para o mercado, porém sem melhoria equivalente na parte operacional. Esse resultado evidencia o argumento de que as estratégias de F\&A podem estar associadas a diversos objetivos, nem sempre relacionados ao aumento da eficiência produtiva ou à geração de sinergia operacional (Lebedev et al., 2015). Com isso retomamos o argumento anterior que a $F \& A$ pode significar uma estratégia de longo prazo para o adquirente, com poucos reflexos no médio prazo.

Por fim, os processos de F\&A do Cluster 2 apresentam resultados expressivos nos três indicadores propostos para a presente pesquisa. Em todos os casos pesquisados desse cluster, as empresas já haviam realizado ao menos um processo anterior que, não raramente, resultou em processos com variações negativas nos indicadores empregados. As características das empresas desse Cluster corroboram a perspectiva proposta por Tanure e Cançado (2005); Milhomem e Hoffmann (2011); e Lebedev et al. (2015), de que a experiência prévia pode ser determinante para o sucesso de um processo de F\&A e representa uma evidência em contrário aos resultados da ANOVA, que comparou as médias de desempenho dos casos de acordo com a quantidade de processos anteriores realizados. Eventualmente não se trata de realizar muitas F\&A para a obtenção de sucesso, mas de promover um processo planejado em que haja a oportunidade de se analisar a priori as possíveis sinergias e criações de valor (Kitching, 1967), assim como de se avaliar a posteriori os resultados efetivamente alcançados, de forma a interiorizar os conhecimentos e capacidades necessários para a obtenção de sucesso. Do ponto de vista da estratégia, considerando os riscos que uma F\&A envolve e os resultados deste estudo, vale a recomendação de Lebedev et al. (2015) sobre implementa-la de forma discreta inicialmente, a ponto de se ampliar a própria curva de aprendizagem.

\section{CONCLUSÕES}

O presente trabalho teve por objetivo caracterizar os processos de F\&A que criaram maior valor interno e sinergia operacional. Foi utilizada uma amostra de 154 processos de F\&A analisados pelo CADE entre 2000 e 2011 e com informações disponíveis no sítio Economática. Foram propostas cinco hipóteses de pesquisa que versavam sobre a influência das características dos processos sobre o desempenho pós-F\&A. As F\&A foram avaliadas a partir da variação percentual de três indicadores: $Q$ de Tobin, VM/VP e ML, sendo que os dois primeiros se referem à criação de valor para o mercado e o último à eficiência operacional. E seu resultado se vê na Tabela 4.

Tabela 4 - Resultados dos Testes de Hipótese

\begin{tabular}{|l|c|}
\hline \multicolumn{1}{|c|}{ HIPÓTESES } & RESULTADO \\
\hline $\begin{array}{l}\text { Hipótese 1 - há diferenças entre os desempenhos dos processos de F\&A } \\
\text { de empresas em diferentes posições da cadeia produtiva. }\end{array}$ & Corroborada. \\
\hline $\begin{array}{l}\text { H1.1 - F\&A Horizontais apresentam melhores desempenhos do que os } \\
\text { demais tipos. }\end{array}$ & Parcialmente Corroborada. \\
\hline $\begin{array}{l}\text { H1.2 - F\&A Verticais apresentam melhores desempenhos do que F\&A } \\
\text { em Conglomerado. }\end{array}$ & Rejeitada. \\
\hline $\begin{array}{l}\text { H2 - Há diferenças entre os desempenhos das empresas a partir dos } \\
\text { processos de F\&A de setores diferentes. }\end{array}$ & Rejeitada. \\
\hline $\begin{array}{l}\text { H3 - Há diferenças entre os desempenhos das empresas a partir dos } \\
\text { processos de F\&A de nacionalidades diferentes. }\end{array}$ & Parcialmente Corroborada. \\
\hline $\begin{array}{l}\text { H4 - A existência de experiência prévia impacta positivamente o } \\
\text { desempenho das F\&A. }\end{array}$ & Rejeitada. \\
\hline
\end{tabular}

Os resultados encontrados reiteram a perspectiva de que a estratégia de F\&A está associada a diversos objetivos. No tocante ao posicionamento das F\&A quanto à posição das empresas na cadeia produtiva, foi possível observar que as F\&A Horizontais apresentam um bom desempenho, tanto em termos de geração de valor de mercado quanto de geração de sinergias, ainda que, no segundo caso, não haja diferenças estatísticas sobre o desempenho de F\&A Verticais. As F\&A em Conglomerado e Verticais, no entanto, mostraram desempenhos contraditórios no tocante às variáveis sobre geração de valor de mercado, o que indica que o resultado da F\&A varia de acordo com o indicador adotado. Podemos observar ainda que, 
as F\&A em Conglomerado não apresentam um bom desempenho em termos de sinergias operacionais.

Ao estudar as F\&A de diferentes setores econômicos, os resultados encontrados indicam haver homogeneidade em termos de desempenho, contrariando a hipótese proposta. Era esperado que por se tratar de processos aglomerativos de empresas de setores distintos as possibilidades de criação de sinergias seriam heterogêneas. Como verificado na revisão de literatura, os motivos de uma F\&A são vários, busca por sinergia, aumento da capacidade de produção, ganhos fiscais, ou até mesmo por motivos menos nobres como erros ao avaliar a empresa-alvo, eliminação de um concorrente ou por simplesmente para maximizar o bem-estar do gerente (Berkovich e Narayanan, 1993; Ross, Westerfield e Jaffe 1995). Esse resultado dialoga com a perspectiva de que nem sempre as F\&A são empregadas com foco na geração de sinergias, sejam operacionais sejam de mercado, e sua adoção pode envolver objetivos de longo prazo difíceis de serem capturas em um trabalho quantitativo.

Um dos principais problemas descritos pela literatura sobre F\&A é a integração de culturas organizacionais distintas. Esse problema seria majorado pelas diferenças culturais na integração entre empresas nacionais e internacionais. Embora os resultados encontrados indiquem que F\&A nacionais apresentam um desempenho superior em termos de geração de valor de mercado, não foi possível identificar o mesmo efeito quando os resultados foram avaliados a partir de indicadores de sinergia operacional. Ao verificar a amostra podemos verificar que diversas empresas internacionais vêm utilizando a estratégia de F\&A para entrada no mercado nacional. Nesse sentido, a F\&A pode ser motivada por objetivos de longo prazo, e que sua análise a luz dos efeitos de curto ou médio prazo sempre são limitados.

Ao verificar a relação entre o quantitativo de processos anteriores e o desempenho de F\&A não se percebemos uma relação positiva entre as variáveis. Para os indicadores de mercado, os resultados indicam que a relação entre as variáveis adota a forma de um "U" invertido. No tocante aos indicadores de sinergia operacional, os resultados foram inversamente proporcionais à quantidade de processos realizados. Isso sugere que, eventualmente, não se trate de simplesmente realizar muitas F\&A, tal como demonstrado pelo resultado não significativo da análise de variância. Para a obtenção de sucesso na estratégia de F\&A, mais importante do que muitos processos de concentração em um processo de tentativa e erro, seria o efetivo planejamento e análise a priori das possíveis sinergias e criações de valor, bem como da avaliação a posteriori os resultados efetivamente alcançados de forma a interiorizar os conhecimentos e capacidades necessários para a obtenção de sucesso. Pode-se concluir que as assertivas de Kitching (1967), um dos autores seminais do tema, cinquenta anos depois, ainda têm validade.
Considerando que diversas categorias criadas possuíam quantidades de casos muito díspares para a comparação das médias a análise de cluster foi empregada para agrupar de acordo com as variáveis de desempenho. Os resultados classificaram os casos em 5 agrupamentos, sendo que os dois mais numerosos (representam $85 \%$ dos casos) apresentaram resultados negativos (piora nos indicadores) e uma melhora discreta nos indicadores, o que ressalta as dificuldades das F\&A e gera dúvidas sobre quão vantajosa pode ser essa estratégia. Os processos de F\&A dos diferentes agrupamentos se distribuíram de forma homogênea pelo período analisado. Nesse sentido, não se identificou a influência do período de realização da F\&A sobre o desempenho, ao menos do ponto de vista de quando ele deveria ser feito.

Não obstante aos resultados encontrados, o presente trabalho possui limitações. A forma de utilização dos indicadores não considera fatores outros ou mesmo a flutuações na economia ao longo do período estudado. Não foi possível isolar o efeito das F\&A de todas as outras decisões estratégicas adotadas pelas empresas que também influenciariam diretamente o desempenho das variáveis empregadas. A influência do período de realização do processo de concentração, bem como diferenças nos processos (fusões, aquisições ou aquisições de negócios) não foram consideradas nas análises. Em que pese a utilização de técnicas post hoc, as diferentes categorias deveriam apresentar quantitativos de casos mais similares para a realização de comparações. Como sugestão para pesquisas futuras, entendemos que pesquisas qualitativas com empresas de múltiplos setores poderiam contribuir para aprofundar os resultados da presente pesquisa e trazer novas explicações sobre as características dos processos de F\&A bem e mal sucedidos. De forma alternativa, a presente pesquisa não indica o impacto dos fatores estudados sobre o desempenho das estratégias de F\&A, sendo essa outra sugestão para pesquisas futuras.

\section{REFERÊNCIAS}

Alexandridis, G.; Petmezas, D.; Travlos, N.G. (2005). Gains from Mergers and Acquisitions Around the World: New Evidence. Financial Management, p. 1671.

Asquith, P.; Bruner, R. F.; Mullins Jr.; D. (1983). The Gains to Bidding Firms from Merger. Journal of Financial Economics, v.11, pp. 121-139.

Barkema, H.; Schijven, M. (2008) How do Firms Learn to Make Acquisitions? A Review of Past Research and an Agenda for the Future. Journal of Management, vol. 34, $n^{\circ} 3$. 
Berkovich, E.; Narayanan, M. P. (1993). Motives for Takeovers: An Empirical Investigation. Journal of Financial and Quantitative Analysis, v.28, n.3, pp. $347-362$.

Binder, M. P.; Maccari, E. A.; Nasser-Carvalho, L. F. (2010). Competência central e lógica dominante: contribuições à análise de processos de fusão e aquisição. Revista de Ciências da Administração, v. 12, n. 28, pp. 83-104.

Bradley, M.; Desai, A.; Kim, E. H. (1988). Journal of Financial Economics, 21, p. 3-40.

Brito, G. A. S.; Batistella, F. D.; Famá, R.(2005). Fusões e aquisições no setor bancário: (...). Revista de Administração da USP, São Paulo, v. 40, n. 4.

Camargos, M. A,; Barbosa, F. V. (2003). Fusões, aquisições e takeovers: um levantamento teórico dos motivos, hipóteses testáveis e evidências empíricas(...). Revista de Gestão da Universidade de São Paulo, São Paulo, v. 10, n. 2, p. 17-38.

(2004). Acordo de fusão

TAM-VARIG: um estudo de caso dos fatores estratégicos, mercadológicos e financeiros e seus impactos sobre os stakeholders. Revista de Gestão da Universidade de São Paulo, São Paulo, v. 11, n. 4, p. 75-91.

(2005). Análise do desempenho econômico financeiro e da criação de sinergias (...) em processos de fusões e aquisições do mercado brasileiro ocorridos entre 1995 e 1999. Revista de Gestão da Universidade de São Paulo, São Paulo, v. 12, n.2.

(2009). Fusões e aquisições de empresas brasileiras: criação de valor e sinergias operacionais(...). Revista de Administração de Empresas, São Paulo, v. 49, n. 2.

Dickerson, A; Gibson, H.; Tsakalotos, E. (1997). The Impact of Acquisitions on Company Performance: Evidence from a Large Panel of UK Firms. Oxford Economic Papers, vol. 49, issue 3, p. 344-61.

Du, K.; Sim, N. (2016). Mergers, acquisitions, and bank efficiency: Cross-country evidence from emerging markets. Research in International Business and Finance, 36, p. 499-510.

Famá, R.; Barros, L. A. (2000). Q de Tobin e seu uso em finanças: aspectos metodológicos e conceituais. Cadernos de Pesquisa em Administração, v. 7, n. 4, p. 27-43.
Field, A. (2005). Discovering Statistics using SPSS. $2^{\mathrm{a}}$ Edição, Sage Publications, London.

Figueira, C.; Nellis, J. (2009). Bank merger and acquisitions activity in the EU: much a do about nothing? The Service Industries Journal, vl. 29, N. 7, July 2009, p.875-886.

Gupta, O.; Roos, G. (2001). Mergers and acquisitions through an intellectual capital perspective. Journal of Intellectual Capital, v.2, n.3, pp.297-309.

Hair Jr., J. F., Black, W. C., Babin, B. J., Anderson, R. E. (2009). Multivariate Data Analisys. $7^{\mathrm{a}}$ Edição, Prentice Hall.

King, D.; Dalton, D. R.; Daily, C.; Covin, J. (2004) Meta-analyses of post-aquisiton performance:indicationsof unidentified moderators. Strategic Management Journal, vol. 25.

Kitching, J. (1967). Why do mergers miscarry? Harvard Business Review, vol. 45, n6.

Kloeckener, G. O. (1994). Fusões e aquisições: motivos e evidência empírica. Revista de Administração, São Paulo, v. 29, n. 1, p. 42-58.

Lebedev, S.; Peng, M. W.; Xie, E.; Stevens, C. E. (2015). Mergers and acquisitions in and out of emerging economies. Journal of World Business, 50, p. 651-662.

Leitão, C. R.; Gali, O. C. (2014). Volatilidade em Fusões e Aquisições: um Estudo no Mercado Brasileiro. Revista Organizações em Contexto, vol. $10, \mathrm{n}^{\circ} 20$.

Malhotra, N. K. (2012). Pesquisa de Marketing: uma orientação aplicada. $6^{\mathrm{a}}$ ed. Porto Alegre: Bookman.

Milhomem, C.; Hoffmann, V. E. (2011). Geração de Eficiências Operacionais a partir da Estratégia de Fusão e Aquisição - um estudo no Brasil entre os anos 2002 e 2008. Anais do V Encontro de Estudos em Estratégia - 3ES, Porto Alegre.

Minadeo, R. (2010). Operações problemáticas de fusões e aquisições. Administração de Empresas em Revista, v. 9, p. 45-64.

Mingoti, S. A. (2005). Análise de Dados Através de Métodos de Estatística Multivariada: uma abordagem aplicada. Belo Horizonte: Editora UFMG.

Motta, L. F. J.; Oliveira, P. V. C.; Cavazotte, F. S. C. N.; Pinto, A. C. F.; Klotzle, M. C. (2013). Criação 
Tipos, Setores, Nacionalidade e Experiência: O Que Importa para o Sucesso das Estratégias De Fusão e Aquisição?

de valor em fusões e aquisições brasileiras. Revista de Administração FACES, v. 12, n. 4, p. 100-119.

Norris Jr., J.T. (2011). China Foreign Direct Investment:Greenfield, Mergers \& Acquisition, Or JointVenture. International Business \& Economics Research Journal. v. 10, n. 1.

Oliveira, T. B. P.; Oliveira, M. R. G. (2015). Abordagem Estocástica na Avaliação EconômicoFinanceira do Processo de Fusões \& Aquisições F\&A: Estudo de Caso da Totvs S/A. Contextus Revista Contemporânea de Economia e Gestão, v. 13 , n. 3, p. 32-56.

Orsi, A. (2006). Gestão do conhecimento em fusões e aquisições: fatores críticos. Revista brasileira de Gestão de Negócios, São Paulo, v. 8, n. 22, p. 4656.

Pardini, D. J.; Santos, R. V.; Machado, D. C.; Azevedo, A. C. (2014) Organizational learning: a functional trajectory perspective in related acquisitions. Revista Gestão \& Planejamento, v. 15, n. 2, p. 341355.

Pasin, R. M.; Matias, A. B. (2001). A geração de sinergias e seus impactos na rentabilidade das empresas no caso de fusões e aquisições. Revista de Administração, São Paulo, v.36, n. 1,.

Patrocínio, M. R.; Kayo, E. K.; Kimura, H. (2005). Intangibilidade e criação de valor nos eventos de fusão e aquisição: uma análise dos retornos anormais no período de 1994 a 2004. In: Anais do Encontro Nacional de Pós-graduação em Administração, 29, Brasília.

Pessanha, G. R. G.; Santos, T. A. D.; Calegario, C. L. L.; Sáfadi, T.; Alcântara, J. N. (2014). Influências das Fusões e Aquisições no valor de mercado das instituições bancárias adquirentes. Contabilidade, Gestão e Governança, v. 17, n. 3, p. 145-158.

Ravenscraft, D. J.; Scherer, F. M. (1987). Life after take over. Journal of Economic Perspectives, [S.I.] v. 36, n. 2 , p. $147-156$.

Rao-Nicholson, R.; Salaber, J.; Cao, T. H. (2016). Long-term performance of mergers and acquisitions in ASEAN countries. Research in International Business and Finance, vol. 36.

Reis, N. R.; Carvalho, F.; Ferreira, J. V. (2015). Um panorama de três décadas de pesquisas de Fusões e
Aquisições. Revista Ibero-Americana de Estratégia - RIAE. Vol. 14, N. 2.

Romano, P. R.; Almeida, V. S. (2015). Análise dos Efeitos em Mercado de Capitais Decorrentes de Fusões: O Caso BRFS.A. Revista de Administração Contemporânea, v. 19, n. 5, p. 606-625.

Ross, S. A.; Westerfield, R.; Jaffe, J. F. (1995). Administração Financeira: Corporate Finance. São Paulo: Atlas.

Sarfati, G.; Shwartzbaum, A. (2013). Sinergias nas fusões e aquisições do setor de educação superior no Brasil. Revista Pensamento Contemporâneo em Administração, v. 7, n. 4, p. 1-23.

Sehnem, S.; Fischer, A.; Turolla, F.; Duarte, T. A. (2015). Desempenho Econômico-Financeiro de um Frigorífico. Revista Eletrônica de Estratégia \& Negócios, v. 8, n. 2, p. 266-293.

Sharma, M. (2010). Determining value creation through mergers and acquisitions in the banking industry using accounting study and event study methodology. European Journal of Economics, Finance and Administrative Sciences, 19, p. 61-73.

Shukla, A.; Gekara, M. G. (2010). Effects of Multinational Mergers and Acquisitions on Shareholders' Wealthand Corporate Performance. The IUP Journal of Accounting Research \& Audit Practices, Vol. IX, N. $1 \& 2$.

Soares, W. B.; Wegner, D.; Dolci, P. C. (2016). Fusão como Estratégia de Crescimento de Redes de Cooperação Empresarial: um estudo de caso em uma rede de farmácias. Revista Ibero-Americana de Estratégia - RIAE, Vol. 15, N. 1.

Suen, A. S.; Kimura, H. (1997). Fusão e aquisição como estratégia de entrada (enter mode) no mercado brasileiro. Revista de Gestão da USP, v. 2, n. 5 , p. 53-60.

Tanure, B.; Cançado, V. L. (2005). Fusões e aquisições: (...) aprendendo com a experiência brasileira. Revista de Administração de Empresas, Rio de Janeiro, v. 45, n. 2, p. 10-22.

Vermuelen, F.; Barkema, H. (2001). Learning through Acquisitions. Academy of Management Journal. Vol. 44, ' 3, pp. 457-476. 